\title{
Sound Generator: Analysis of the Effectiveness of Noise in the Habituation of Tinnitus
}

\author{
Maria Fernanda Capoani Garcia Mondelli ${ }^{10} \quad$ Aline Faure Cabreira ${ }^{1}$ (i) $\quad$ Izabella Lima de Matos ${ }^{10}$ \\ Maria Carolina Ferreira ${ }^{10}$ Andressa Vital Rocha ${ }^{1}{ }^{\circledR}$ \\ ${ }^{1}$ Faculdade de Odontologia de Bauru, Universidade de São Paulo, \\ Bauru, SP, Brazil \\ Int Arch Otorhinolaryngol 2021;25(2):e205-e212. \\ Address for correspondence Maria Fernanda Capoani Garcia \\ Mondelli, PhD, Fonoaudiologia, Faculdade de Odontologia de Bauru, \\ Universidade de São Paulo, Al. Octavio Pinheiro Brisola 9-75, Bauru, \\ SP, 17012-901, Brazil (e-mail: mfernandamondelli@hotmail.com).
}

\begin{abstract}
Introduction Tinnitus is a disorder that affects 10 to $15 \%$ of de world's population. Sound therapy performed through hearing aids (HAs) with integrated sound generator (SG) is one of the forms of tinnitus treatment.

Objective To analyze the effectiveness of four masking noises in relieving tinnitus in individuals with mild and moderate bilateral sensorineural hearing loss and their influence in speech perception.

Methods The participants were 35 individuals with tinnitus and mild and moderate bilateral sensorineural hearing loss, divided into four groups. All groups underwent HA and SG adaptation, being regulated in the combined mode (HA and SG). In group 1 (G1), the white noise stimulus was applied, in group 2 (G2), pink noise was applied, in group 3 (G3), speech noise, and in group 4 (G4), the high tone was applied. All patients were subjected to the following procedures: audiological diagnosis, acuphenometry, tinnitus handicap inventory (THI), visual analogue scale (VAS), and hearing in noise test (HINT). The procedures were performed prior to and after hearing intervention, and after 3 months of use of HA and SG.

Results All groups presented a statistically significant difference for the THI, VAS, and HINT pre and postintervention. In the case of the HINT, only pink noise presented a significant difference. However, in the comparation among groups there was no

Keywords

- tinnitus

- hearing loss

- hearing aids significant difference.

Conclusion The present study made it possible to conclude that the four noises were equally effective in relieving tinnitus, with no statistically significant differences between the analyzed groups.
\end{abstract}

\section{Introduction}

Tinnitus is defined as a conscious perception of a sound in the ears or head without stimulation of an external sound source. ${ }^{1}$ It is a very prevalent complaint, affecting $\sim 10$ to $15 \%$ of the world population, influencing the quality of life. ${ }^{2,3}$

received

July 18,2019

accepted

April 5, 2020

published online

June 23, 2020
DOI https://doi.org/

10.1055/s-0040-1713377. ISSN 1809-9777.
Due to the difficulty in measuring and treating tinnitus, some evaluations become important in establishing parameters, such as acuphenometry, the use of the visual analogue scale (VAS) and questionnaires of impacts on a patient's quality of life, such as the tinnitus handicap inventory (THI). ${ }^{4}$

\footnotetext{
(c) 2020. Fundação Otorrinolaringologia. All rights reserved.

This is an open access article published by Thieme under the terms of the Creative Commons Attribution-NonDerivative-NonCommercial-License, permitting copying and reproduction so long as the original work is given appropriate credit. Contents may not be used for commercial purposes, or adapted, remixed, transformed or built upon. (https://creativecommons.org/ licenses/by-nc-nd/4.0/)

Thieme Revinter Publicações Ltda., Rua do Matoso 170, Rio de Janeiro, RJ, CEP 20270-135, Brazil
} 
To heal the complaint of tinnitus, various forms of interventions are used to minimize the occasioned uncomfortable feeling. Tunkel et $\mathrm{al}^{5}$ cite several therapeutic proposals such as: hearing aids (HAs), sound generator (SG), biofeedback, nutritional guidelines, and electrical stimulation, among others.

The process of habituation of tinnitus through sound therapy consists of stimulating the ears with the presence of constant and neutral noises to reduce their hypersensitivity in silence. Sound generators, associated or not with auditory amplification, may be used at low intensity to avoid tinnitus, providing a reduction in tinnitus perception. ${ }^{4}$ Thus, auditory stimulation has the capacity to interfere in the central auditory representation of tinnitus, diminishing its perception. ${ }^{6}$

The SG has been used in tinnitus intervention when it is not attenuated with the use of HAs alone. The proposal is the adaptation of a combined device: amplification and SG. ${ }^{7}$ Sound generators produce neutral sound stimuli that should be audible and comfortable to the patient.

The masking level is a key difference among sound therapies. ${ }^{8}$ To achieve habituation, noise should not mask the tinnitus; instead, both sounds must be perceived: the sounds of noise and tinnitus itself. ${ }^{9}$

A study on plasticity indicates that the increase of the auditory stimulus provided by sound amplification can lead to secondary plasticity, contributing to the reduction of tinnitus discomfort and favoring speech recognition throughout the acclimatization period. ${ }^{10}$

Acclimatization refers to the phase that follows the adaptation of HAs, when there is a progressive improvement of hearing abilities and speech recognition resulting from the new clues available to the user of sound amplification. ${ }^{11}$ Thus, it is of fundamental importance to carry out evaluations of speech recognition in this population, making possible the improvement of this ability concomitant to the treatment of the symptom. $^{12}$

Sound therapy performed through the HA combined with a SG has been gaining prevalence in auditory health services, ${ }^{13}$ thus requiring research that bases the decision of the professionals and guide the use of this device.

The aim of the present work was to analyze the efficacy of four noises and their influence on tinnitus relief and speech perception in individuals with bilateral sensorineural hearing loss.

\section{Method}

The study was conducted at a school clinic, after obtention of consent from the patients for the participation of the work and publication of the data and approval of the Committee of Ethics in Research - 1.198.851.

The research was conducted as a randomized clinical trial with stratified sample according to gender and age group, using the program http://randomizer.org/form.htm, which defined which of the four groups the individual would belong to.

\section{Sample Characterization}

To make it possible to characterize the sample, the authors outlined the eligibility criteria. Thus, patients from a hearing health service who met the eligibility criteria were invited to participate in the study.

\section{Inclusion Criteria Were}

- Subjects with diagnosis of mild or moderate bilateral symmetrical sensorineural hearing loss;

- Age range 55 to 70 years old;

- Both genders;

- Complaint of chronic tinnitus (daily and for more than six months) in both ears;

- Absence of previous experience using HAs or any sound intervention;

- Score in the THI $\geq 18$ (degree of mild discomfort);

- After adaptation, present effective use of HAs during the course of the study;

- Attend the returns scheduled by the service.

Exclusion criteria:

- Hearing loss with diagnosis of Meniere Disease;

- Previous realization of some type of intervention for the tinnitus (hearing aids, sound generator, counseling, medication or any other intervention).

\section{Constitution of the Sample}

The sample consisted of 35 patients, $31.4 \%$ of whom were women and $68.6 \%$ who were men, with a mean age of 68.43 years and a standard deviation (SD) of 12.69 years.

The specimen consisted of 36 individuals, divided into four groups, each group being composed of 9 individuals.

All groups were bilaterally adapted, and the HAs were programmed in the combined mode: amplification and SG activated, differentiating only in the type of stimulus offered. Thus, the groups were divided as follows: group 1 white noise; group 2 pinknoise; group 3 speech noise; group 4 high tone noise.

Noise activations were performed by a "blinded" speech therapist. The speech therapist who performed the adjustment of the device was not the main researcher; therefore, resuming the precepts of randomization, this second speech therapist ("blinded") made the necessary adjustments related to the presentation of noise with each patient.

\section{Procedures}

Initially, all patients were guided by the tinnitus activities treatment (TAT), ${ }^{14}$ organized in a reduced form, following the topics: "Auditory system"; "What is tinnitus: prevalence, common causes, relation to hearing loss"; "Explanation of sound therapy" and "Treatment: sound therapy, process of habituation of tinnitus."

\section{Audiological Diagnosis}

The subjects underwent visual inspection of the external auditory meatus to verify the occurrence of some impairment of the middle and/or outer ear, audiological evaluation including high frequency tone audiometry (HFTA) and immittance testing to rule out middle and external ear factors.

The procedures were performed in an acousticallytreated room, the HFTA in an acoustic booth with the AC40 audiometer (Interacoustics, Middelfart, Denmark) 
and HDA-200 earphones (Sennheiser Electronic Corporation 1 Enterprise Drive, Old Lyme, CT, USA), warble stimulus, both with the appropriate calibrations and the immittanciometry in the AT 235 (Interacoustics Audiometer Allé 5500 Middelfart, Denmark) equipment.

To classify patients as having either hearing loss or normal hearing, the mean thresholds in $\mathrm{dB}$ HL at 500, 1,000, 2,000, and $4,000 \mathrm{~Hz}$ were used. Using the World Health Organization criteria, mean hearing thresholds $\leq 25 \mathrm{~dB}$ HL indicated normal hearing and $>25 \mathrm{~dB}$ HL indicated hearing loss. Hearing loss was further characterized as mild (mean $26-40 \mathrm{~dB}$ $\mathrm{HL}$ ), moderate (mean 41-60 dB HL), severe (mean 61-80 dB $\mathrm{HL}$ ), and profound (mean $>80 \mathrm{~dB} \mathrm{HL}$ ).

In this objective, hyperacusis has not been researched.

\section{Tinnitus Assessment}

\section{- Application of the THI questionnaire:}

Translated and validated for Brazilian Portuguese, ${ }^{15}$ the questionnaire consists of 25 questions that must be answered with "yes" (4 points), "sometimes" ( 2 points) and "no" (0 points). The higher the score, the greater the repercussion of tinnitus in the patient's quality of life. The THI evaluates the tinnitus handicap by measuring its general nuisance and other domains: functional, emotional, and catastrophic.

The total test score ranges from 0 to 100 points, which can be classified as follows:

- 0 to 16 points: slight or no handicap;

- 18 to 36 points: mild handicap;

- 38 to 56 points: moderate handicap;

- 58 to 76 points: severe handicap;

- 78 to 100 points: catastrophic handicap.

\section{- Application of the VAS:}

The VAS assists in the assessment of the annoyance of tinnitus for the individual. It is an important tool to verify the evolution of the patient during the treatment, used at the beginning and at the end of each treatment.

The scale consists of a "ruler," with progressive graphical representations equivalent to grades from 0 to $10,{ }^{16}$ with higher grades corresponding to higher the tinnitus discomfort.

\section{- Psychoacoustic measures of tinnitus:}

Tinnitus was subjectively measured by acuphenometry, suggesting the loudness and pitch in which this auditory sensation occurs. The test was performed in an acoustic cabin with an AC40 audiometer (Interacoustics Audiometer Allé 5500 Middelfart, Denmark)

Initially, the pitch (frequency sensation) of tinnitus was investigated using pure tone or narrowband noise, depending on the characterization of the symptom presented by the individual. The stimuli were presented $15 \mathrm{~dB}$ above the audiometric thresholds, initiated at the frequency of $1,000 \mathrm{~Hz}$.

Subsequently, a loudness (intensity sensation) study was performed on the previously estimated tinnitus frequency and its audibility threshold, with the signal being increased $1 \mathrm{~dB}$ at a time until the patient reported it being equivalent to the symptom. The values of tinnitus sensation level were considered as results, with the difference between the sound intensity of the tinnitus and the audiometric threshold at the same frequency being expressed in decibel sensation level (dBSL).

The patients had bilateral tinnitus, so the attempts were gradual and successive, with higher and lower tones until a tone close to tinnitus was reached. ${ }^{17,18}$

For the minimum masking level (MML) search, the narrow band stimulus was used, being presented to the patient ascendingly in order to evaluate the lowest sound intensity that can mask tinnitus. ${ }^{17,18}$

In the occurrence of tinnitus remission (total or partial), the measurements were not performed again due to the absence of the symptom.

\section{Assessment of Speech Perception}

The evaluation of speech perception was performed through the hearing in noise test (HINT) adapted to Brazilian Portuguese. ${ }^{19}$ The HINT is an adaptive test in which the individual is asked to recognize and repeat simple sentences in silence and noise (composite noise).

Twelve sentence lists were used in a random manner according to the distribution of the test, and the intensity of presentation was variable until the sentence recognition threshold (SRT/HINT) was obtained, when $50 \%$ of sentences were correctly repeated, with noise in the fixed intensity of $65 \mathrm{dBHL}$ in the following situations: speech in silence (S) and speech with frontal noise (FN), which was calculated by the HINTPro 7.2 audiometric system software (Bio-Logic Systems Corp. Phone: (800) 323-8326 1 Bio-Logic Plaza, Mundelein, IL 60060, USA), an equipment that provides the HINT test by means of a weighted average.

The evaluation of speech perception was performed in two stages, on the day of adaptation of the HAs (without the devices) and after 3 months of effective use (with the devices).

\section{Adaptation and Verification of the Hearing Aid}

All subjects were matched with a mini retroauricular HA, with thin tube and olives, with programming in company-specific software, using the noise spectrum set by the manufacturer and adjusted according to the individual needs and observations of the patient. The devices were set in the combined mode (amplification and SG activated in the same program).

The noise adjustment was performed in ascending order, seeking the lowest intensity capable of promoting some tinnitus relief.

Following the programming of the HAs, the verification procedure was performed using probe microphone measurements using the Aurical Free Fit equipment (Natus Medical Denmark APS, Hoerskaetten 9, 2630, Taastrup, Denmark). Real-ear aided response (REAR) values with a HA were compared with the targets of the National Acoustic Laboratories-nonlinear fitting procedure, version 2 (NALNL2) prescriptive rule for weak, medium, and strong sounds. For all the subjects, the answers were assimilated to the targets. 
Table 1 Characterization of the degrees of hearing loss

\begin{tabular}{|l|l|l|l|l|}
\hline & \multicolumn{2}{|l|}{$\begin{array}{l}\text { Degree of } \\
\text { hearing loss } \\
\text { right ear (dB) }\end{array}$} & \multicolumn{2}{l|}{$\begin{array}{l}\text { Degree of } \\
\text { hearing loss } \\
\text { left ear (dB) }\end{array}$} \\
\hline & Mild & Moderate & Mild & Moderate \\
\hline Group A (n) & $66.7 \%$ & $33.3 \%$ & $44.4 \%$ & $55.6 \%$ \\
\hline Group B (n) & $25.0 \%$ & $75.0 \%$ & $37.5 \%$ & $62.5 \%$ \\
\hline Group C (n) & $55.7 \%$ & $44.4 \%$ & $33.3 \%$ & $66.7 \%$ \\
\hline Group D (n) & $66.7 \%$ & $33.3 \%$ & $66.7 \%$ & $33.3 \%$ \\
\hline
\end{tabular}

Abbreviations: $d B$, decibel; $n$, sample.

The final evaluation occurred after 3 months of combined adaptation to collect information necessary for the comparative analysis of the groups regarding the level of annoyance of tinnitus. The effective use of Has was confirmed by means of datalogging and the 3-month period determined based on the studies. ${ }^{17,18,20}$

\section{Form of Analysis}

Data were recorded in Microsoft Office Excel (Microsoft Corp., Redmond, WA, USA), from the distribution of patients between groups. These data were tabulated and described according to the descriptive statistical analysis of all variables studied (means and standard deviations for quantitative variables and mean, median, 1 st and 3rd quartile for ordinal qualitative variables). Previously, in the performance of the statistical tests, the normality of the data was verified by the Kolmogorov-Smirnov method. Intra and intergroup differences were analyzed, as well as the changes between the experimental periods. The analysis of the results was performed based on the inductive or inferential statistics of the data collected, allowing the researcher to go beyond the description of the data collected in the sample, making inferences about the sample collected from a given population.

For the intra- and intergroup comparisons, pre-and postintervention, we used the $t$-paired test and the analysis of variance for a criterion for the quantitative variables and for the ordinal qualitative variables, the Chi-saquare test was used.

In all statistical tests, a significance level of $5 \%$ was adopted (values of $p<0.05$ were considered as indicative of significance).

\section{Results}

Concerning hearing loss, $41.7 \%$ of the patients presented bilateral mild degree loss, $41.7 \%$ moderate bilateral, and $16.7 \%$ mild degree in one ear and moderate in the contralateral ear ( - Table 1). All patients presented type A tympanometric curve.

Concerning the investigation of the thresholds in the anterior auditory field (AAF) $(9-20 \mathrm{kHz})$, all the thresholds found were above the zero-hearing threshold. Such thresholds have already been discussed in a previous study. ${ }^{21}$

The results described below refer to the comparison before and after within each group.

Psychoacoustic measures were not performed in all patients in the final evaluation, since $42.9 \%$ of them returned without tinnitus complaint, due to partial or total remission of the symptom. Thus, - Table 2 determines the mean values and standard deviation of the measurements obtained in the acuphenometry in each group, only in the initial evaluation.

- Table 3 describes the mean and standard deviation values of the THI obtained in each group, pre and postintervention using the $t$-paired test and the difference between these moments, the standard deviation, and the $p$ value for each group in the THI questionnaire.

According to - Table 3, all groups presented a statistically significant difference for the THI questionnaire in all domains, reduced from moderate to negligible/discrete.

- Table 4 describes the VAS mean and standard deviation values obtained in each group, pre and postintervention, and the difference between these moments, the standard deviation, and the $p$-value for each group in the VAS.

According to - Table 4, all groups presented a statistically significant difference, reduced from moderate to mild annoyance.

- Table 5 describes the HINT mean and standard deviation values obtained in each group, pre and postintervention, and the difference between these moments, the standard deviation, and the $p$-value for each group, in the HINT test in speech situations in silence and front noise.

According to $\mathbf{- T a b l e ~} \mathbf{5}$, all groups presented a statistically significant difference in the speech situation in silence. However, in FN, G2 was the only one that presented a significant difference.

In the comparison between groups, there was a statistically significant difference only in FN for G2. In the other evaluations, no significant differences were found.

\section{Discussion}

The age group of the study sample was composed of individuals with a mean age of 68.43 years. There was a higher prevalence of males (68.6\%). The degree of hearing loss presented in the studied sample was $41.7 \%$ of bilateral

Table 2 Mean values and standard deviation of the psychoacoustic measures in the initial evaluation

\begin{tabular}{|l|l|l|l|l|}
\hline \multirow{2}{*}{ Acuphenometry } & G1 & G2 & G3 & G4 \\
\cline { 2 - 5 } & Mean SD (dB) & Mean SD (dB) & Mean SD (dB) & Mean SD (dB) \\
\hline Pitch (kHz) & $3.30 \pm 2.31$ & $4.37 \pm 2.66$ & $3.72 \pm 2.51$ & $5.44 \pm 2.24$ \\
\hline Loudness (dBSL) & $8.56 \pm 4.61$ & $7.13 \pm 2.74$ & $5.22 \pm 2.53$ & $7.22 \pm 5.09$ \\
\hline MML & $8.00 \pm 4.69$ & $12.25 \pm 7.40$ & $10.89 \pm 7.44$ & $10.00 \pm 10.03$ \\
\hline
\end{tabular}

Abbreviations: dB, decibel; dBSL, decibel sensation level; MML, minimum masking level; SD, standard deviation. 
Table 3 Mean and standard deviation before and after intervention and the difference between these moments, standard deviation and $p$-value for the THI questionnaire

\begin{tabular}{|c|c|c|c|c|c|c|c|c|}
\hline & \multicolumn{2}{|l|}{ Total } & \multicolumn{2}{|l|}{ Functional } & \multicolumn{2}{|l|}{ Emotional } & \multicolumn{2}{|c|}{ Catastrophic } \\
\hline & Prescore & Postscore & Prescore & Postscore & Prescore & Postscore & Prescore & Postscore \\
\hline \multicolumn{9}{|l|}{ Group 1} \\
\hline Mean SD & $\begin{array}{l}44.22 \pm \\
9.45\end{array}$ & $\begin{array}{l}10.89 \pm \\
5.57\end{array}$ & $\begin{array}{l}17.11 \pm \\
6.41\end{array}$ & $\begin{array}{l}3.11 \pm \\
3.01\end{array}$ & $\begin{array}{l}18.22 \pm \\
5.86\end{array}$ & $\begin{array}{l}5.33 \pm \\
3.00\end{array}$ & $\begin{array}{l}8.89 \pm \\
4.13\end{array}$ & $\begin{array}{l}2.44 \pm \\
2.60\end{array}$ \\
\hline Difference & \multicolumn{2}{|c|}{$-33.33 \pm 8.94$} & \multicolumn{2}{|c|}{$-14.00 \pm 5.91$} & \multicolumn{2}{|c|}{$-12.88 \pm 6.00$} & \multicolumn{2}{|c|}{$-6.44 \pm 4.21$} \\
\hline$P$-value & \multicolumn{2}{|l|}{$0.000^{*}$} & \multicolumn{2}{|l|}{$0.000^{*}$} & \multicolumn{2}{|l|}{$0.000^{*}$} & \multicolumn{2}{|l|}{$0.002^{*}$} \\
\hline \multicolumn{9}{|l|}{ Group 2} \\
\hline Mean SD & $\begin{array}{l}54.75 \pm \\
25.11\end{array}$ & $\begin{array}{l}12.25 \pm \\
20.07\end{array}$ & $\begin{array}{l}22.00 \pm \\
12.96\end{array}$ & $\begin{array}{l}5.00 \pm \\
8.94\end{array}$ & $\begin{array}{l}21.00 \pm \\
11.46\end{array}$ & $\begin{array}{l}5.00 \pm \\
7.32\end{array}$ & $\begin{array}{l}11.75 \pm \\
3.28\end{array}$ & $\begin{array}{l}2.25 \pm \\
4.20\end{array}$ \\
\hline Difference & \multicolumn{2}{|c|}{$-43.50 \pm 19.26$} & \multicolumn{2}{|c|}{$-17.00 \pm 10.14$} & \multicolumn{2}{|c|}{$-16.00 \pm 10.25$} & \multicolumn{2}{|c|}{$-9.50 \pm 2.33$} \\
\hline$P$-value & \multicolumn{2}{|l|}{$0.000^{*}$} & \multicolumn{2}{|c|}{$0.002^{*}$} & \multicolumn{2}{|l|}{$0.003^{*}$} & \multicolumn{2}{|l|}{$0.000^{*}$} \\
\hline \multicolumn{9}{|l|}{ Group 3} \\
\hline Mean SD & $\begin{array}{l}45.78 \pm \\
14.71\end{array}$ & $\begin{array}{l}12.44 \pm \\
14.17\end{array}$ & $\begin{array}{l}20.44 \pm \\
8.11\end{array}$ & $\begin{array}{l}6.22 \pm \\
4.63\end{array}$ & $\begin{array}{l}17.11 \pm \\
6.86\end{array}$ & $\begin{array}{l}5.11 \pm \\
8.19\end{array}$ & $\begin{array}{l}8.22 \pm \\
2.72\end{array}$ & $\begin{array}{l}1.33 \pm \\
2.64\end{array}$ \\
\hline Difference & \multicolumn{2}{|c|}{$-33.33 \pm 20.66$} & \multicolumn{2}{|c|}{$-14.22 \pm 10.50$} & \multicolumn{2}{|c|}{$-12.00 \pm 9.32$} & \multicolumn{2}{|c|}{$-6.88 \pm 3.75$} \\
\hline$P$-value & \multicolumn{2}{|c|}{$0.001^{*}$} & \multicolumn{2}{|l|}{$0.004^{*}$} & \multicolumn{2}{|c|}{$0.005^{*}$} & \multicolumn{2}{|c|}{$0.001^{*}$} \\
\hline \multicolumn{9}{|l|}{ Group 4} \\
\hline Mean SD & $\begin{array}{l}45.56 \pm \\
15.32\end{array}$ & $\begin{array}{c}16.00 \pm \\
17.17\end{array}$ & $\begin{array}{l}19.78 \pm \\
9.61\end{array}$ & $\begin{array}{l}6.89 \pm \\
7.21\end{array}$ & $\begin{array}{l}15.78 \pm \\
6.51\end{array}$ & $\begin{array}{l}6.67 \pm \\
8.54\end{array}$ & $\begin{array}{l}9.56 \pm \\
2.40\end{array}$ & $\begin{array}{l}3.11 \pm \\
3.62\end{array}$ \\
\hline Difference & \multicolumn{2}{|c|}{$-29.55 \pm 16.21$} & \multicolumn{2}{|c|}{$-12.88 \pm 10.44$} & \multicolumn{2}{|c|}{$-9.11 \pm 5.39$} & \multicolumn{2}{|c|}{$-6.44 \pm 5.07$} \\
\hline$P$-value & $0.001^{*}$ & & $0.006^{*}$ & & $0.001^{*}$ & & $0.005^{*}$ & \\
\hline
\end{tabular}

Abbreviation: SD, standard. Deviation, THI, tinnitus handicap inventory. *Significant values $(p<0.05)$.

mild degree, $41.7 \%$ of moderate bilateral degree, and $16.7 \%$ of mild and moderate degree (- Table $\mathbf{1}$ ).

In the study of high frequencies, the occurrence of audiometric curves with thresholds below of zero for the whole sample was verified. The values found were expected since the high frequencies are the first to be affected in the majority of sensorineural hearing losses. ${ }^{22}$

Regarding the psychoacoustic measures, $42.9 \%$ of the patients did not present tinnitus at the time of the final evaluation, so it was not possible to compare the results before and after the intervention, only to describe the results of the initial evaluation (-Table 2). However, this outcome can be considered a positive result since it suggests that the use of amplification associated with noise provided an improvement in tinnitus, allowing us to infer that these patients went through the process of habituation and presented partial or even total remission of the symptom.

In the total sample, the average frequency of tinnitus was $4,207 \mathrm{~Hz}$. Similar results were found in the study by Carrabba et $\mathrm{al}^{20}$ in which the average frequency of his sample was $5,333 \mathrm{~Hz}$. Corroborating with the work, ${ }^{23}$ who reported an acute pitch prevalence (80\%) in their sample, concluding that there is a predominance of these frequencies in acuphenometry. This result was already expected since the sample of the present study consisted of patients with sensorineural hearing loss and according to Menezes and
Santos, ${ }^{24}$ cochlear compromises usually generate tinnitus with more tone height.

The mean loudness of tinnitus was $7.03 \mathrm{dBSL}$ of loudness, and the mean MML was $10.23 \mathrm{dBSL}$. These values were similar to the study by Carrabba et al, ${ }^{20}$ which pointed out an average of 5 to $10 \mathrm{dBSL}$ above the auditory threshold of the determined frequency for the two measurements.

In the initial evaluation, auditory preintervention, the total sample had an average THI of 47.37 points, which, according to the classification, corresponds to the degree of moderate discomfort. It is worth mentioning that although the mean value of this value was found, $25.7 \%$ of the patients reached the hearing health service with a severe or catastrophic degree of discomfort.

Research reported that patients with tinnitus complaints may present varying degrees of discomfort with the symptom, having a greater or lesser impact on their quality of life. ${ }^{25}$

In the comparison of the THI pre and postintervention (-Table 3), there was a statistically significant difference in all groups, indicating the benefit of SG in relation to decreased tinnitus sensation. These findings corroborate with studies found in the literature that obtained positive results with a SG associated with amplification. 4,17,20,26,27

The THI was used as a method of evaluation in several studies, ${ }^{4,28-30}$ being considered a valid instrument due to the aspects addressed, its reliability, and for being easy to interpret. $^{31}$ 
Table 4 Mean and standard deviation before and after auditory intervention and the difference between these moments, standard deviation and $p$-value for VAS

\begin{tabular}{|c|c|c|}
\hline & Prescore & Postscore \\
\hline \multicolumn{3}{|l|}{ Group 1} \\
\hline Mean SD & $7.67 \pm 1.22$ & $4.44 \pm 1.50$ \\
\hline Difference & \multicolumn{2}{|l|}{-3.22} \\
\hline SD & \multicolumn{2}{|l|}{1.64} \\
\hline$P$-value & \multicolumn{2}{|l|}{$0.000^{*}$} \\
\hline \multicolumn{3}{|l|}{ Group 2} \\
\hline Mean SD & $7.25 \pm 1.28$ & $3.88 \pm 2.80$ \\
\hline Difference & \multicolumn{2}{|l|}{-3.37} \\
\hline SD & \multicolumn{2}{|l|}{1.92} \\
\hline$P$-value & \multicolumn{2}{|l|}{$0.002^{*}$} \\
\hline \multicolumn{3}{|l|}{ Group 3} \\
\hline Mean SD & $6.56 \pm 1.42$ & $3.00 \pm 2.50$ \\
\hline Difference & \multicolumn{2}{|l|}{-3.55} \\
\hline SD & \multicolumn{2}{|l|}{1.81} \\
\hline$P$-value & \multicolumn{2}{|l|}{$0.000^{*}$} \\
\hline \multicolumn{3}{|l|}{ Group 4} \\
\hline Mean SD & $6.56 \pm 2.06$ & $3.11 \pm 2.75$ \\
\hline Difference & \multicolumn{2}{|l|}{-3.44} \\
\hline SD & \multicolumn{2}{|l|}{1.81} \\
\hline$P$-value & \multicolumn{2}{|l|}{$0.000^{*}$} \\
\hline
\end{tabular}

Abbreviation: SD, standard deviation; VAS, visual analogue scale. *Significant values $(p<0.05)$.

The VAS is considered a simple, fast, and highly valuable method, ${ }^{32}$ and it is widely applied, as well as the THI, in tinnitus studies conducted in Brazil. ${ }^{28,33}$

In the present study, VAS scores were significantly reduced in all groups (-Table 4), with an initial overall mean of 7 (moderate degree) and a mean of 3.25 (mild grade). These results reveal the relationship between the two evaluation methods: the VAS and the THI since they presented proportional responses in the two moments of application.

Figueiredo et $\mathrm{al}^{33}$ performed a study with 43 patients with mean age of 62.85 years who presented tinnitus and sensorineural hearing loss to analyze the correlation of these two instruments and verified that there is a significant correspondence between them, so that the higher the VAS score, the higher the THI score, which in the opinion of the authors makes the results even more reliable.

The difficulty in speech perception is one of the complaints reported by patients with tinnitus in a clinical situation. Recent research suggests that tinnitus can affect speech recognition, ${ }^{34-36}$ and any contribution on this subject is therefore necessary to obtain more information on the actual extent of this symptom in this ability.

Therefore, the present study aimed to evaluate, through the HINT test, the influence of noise associated with amplification in the improvement of speech perception. As
Table 5 Mean and standard deviation before and after auditory intervention and the difference between these moments, standard deviation and p-value for the HINT test

\begin{tabular}{|c|c|c|c|c|}
\hline & \multicolumn{2}{|l|}{ HINT - S } & \multicolumn{2}{|c|}{ HINT - FN } \\
\hline & $\begin{array}{l}\text { Pre } \\
\text { (dBPL) }\end{array}$ & $\begin{array}{l}\text { Post } \\
\text { (dBPL) }\end{array}$ & $\begin{array}{l}\text { Pre } \\
\text { (dBPL) }\end{array}$ & $\begin{array}{l}\text { Post } \\
\text { (dBPL) }\end{array}$ \\
\hline \multicolumn{5}{|l|}{ Group 1} \\
\hline Mean SD & $\begin{array}{l}55.26 \pm \\
8.05\end{array}$ & $\begin{array}{l}44.83 \pm \\
5.17\end{array}$ & $\begin{array}{l}2.01 \pm \\
3.08\end{array}$ & $\begin{array}{l}0.80 \pm \\
1.39\end{array}$ \\
\hline Difference & \multicolumn{2}{|l|}{-10.44} & \multicolumn{2}{|l|}{-1.2} \\
\hline SD & \multicolumn{2}{|l|}{9.89} & \multicolumn{2}{|l|}{3.11} \\
\hline$P$-value & \multicolumn{2}{|l|}{$0.013^{*}$} & \multicolumn{2}{|l|}{0.277} \\
\hline \multicolumn{5}{|l|}{ Group 2} \\
\hline Mean SD & $\begin{array}{l}59.06 \pm \\
7.85\end{array}$ & $\begin{array}{l}48.58 \pm \\
9.61\end{array}$ & $\begin{array}{l}5.18 \pm \\
2.68\end{array}$ & $\begin{array}{l}2.45 \pm \\
2.54\end{array}$ \\
\hline Difference & \multicolumn{2}{|l|}{-10.47} & \multicolumn{2}{|l|}{-2.73} \\
\hline SD & \multicolumn{2}{|l|}{8.55} & \multicolumn{2}{|l|}{1.64} \\
\hline$P$-value & \multicolumn{2}{|l|}{$0.011^{*}$} & \multicolumn{2}{|l|}{$0.002^{*}$} \\
\hline \multicolumn{5}{|l|}{ Group 3} \\
\hline Mean SD & $\begin{array}{l}54.94 \pm \\
8.62\end{array}$ & $\begin{array}{l}44.81 \pm \\
6.21\end{array}$ & $\begin{array}{l}1.80 \pm \\
2.11\end{array}$ & $\begin{array}{l}1.04 \pm \\
1.35\end{array}$ \\
\hline Difference & \multicolumn{2}{|l|}{-10.13} & \multicolumn{2}{|l|}{-0.75} \\
\hline SD & \multicolumn{2}{|l|}{7.44} & \multicolumn{2}{|l|}{1.94} \\
\hline$P$ & \multicolumn{2}{|l|}{$0.004^{*}$} & \multicolumn{2}{|l|}{0.278} \\
\hline \multicolumn{5}{|l|}{ Group 4} \\
\hline Mean SD & $\begin{array}{l}58.47 \pm \\
8.42\end{array}$ & $\begin{array}{l}45.06 \pm \\
6.33\end{array}$ & $\begin{array}{l}3.10 \pm \\
2.95\end{array}$ & $\begin{array}{l}1.98 \pm \\
3.50\end{array}$ \\
\hline Difference & \multicolumn{2}{|l|}{-13.40} & \multicolumn{2}{|l|}{-1.11} \\
\hline SD & \multicolumn{2}{|l|}{7.75} & \multicolumn{2}{|l|}{1.97} \\
\hline$P$ & \multicolumn{2}{|l|}{$0.001^{*}$} & \multicolumn{2}{|l|}{0.130} \\
\hline
\end{tabular}

Abbreviations: dBPL, decibel presentation level; FN, front noise; HINT, hearing in noise test; $S$, silence; SD, standard deviation.

*Significant values $(p<0.05)$.

answers, it was possible to observe a significant difference in silence for all groups after 3 months of acclimatization (-Table 5). Similar results were found in a study by Santos, ${ }^{17}$ who adapted a SG in 30 individuals divided into 2 groups: 15 with tinnitus and normal hearing and 15 with tinnitus and hearing loss, and in the speech perception test in the situation of silence, the author observed an improvement for both groups evaluated.

In FN, it was observed that G2 was the only group that had a statistically significant difference ( - Table 5 ). This result makes us reflect on the difference in the performance of the patients in this group who were exposed to pink noise, and the possible variables that may have influenced the improvement of speech perception, especially in the noise situation.

To better understand the correlation of noise used in G2 and the significant improvement in speech perception, it is necessary to seek information about the benefits of pink noise to brain activity. 
Zhou et $\mathrm{al}^{37}$ performed a study with 50 individuals to evaluate the effect of pink noise on sleep quality, in which subjects were exposed to noise and silence and evaluated in both conditions. Among the tests performed, it was possible to observe that the pink noise caused a decrease in the signs of an electroencephalogram and cardiopulmonary condition, resulting from a reduction in brain activity. Thus, the authors concluded that it has a significant effect on brain wave reduction and sleep stability in individuals, improving the quality of the brain.

Correlating with the present study, it is suggested that tinnitus is a result of a hyperactivity of the central nervous system (CNS), which remains increased to compensate for the reduction of cochlear nerve activity after cochlear lesions. ${ }^{38}$ Therefore, we can infer that one of the possibilities for G2 to be highlighted was the pink noise stimulus, which contributed to the reduction of this hyperactivity of the CNS and, consequently, of tinnitus, favoring speech perception especially in this group.

Another issue that should be taken into account, even in relation to the benefits of pink noise, is the relaxation it causes. ${ }^{37}$ It is believed that relaxation provides an increase in concentration, especially in patients with associated emotional factors, since, in many cases, tinnitus directly interferes with daily activities, causing behavioral changes, including anxiety, frustration, irritability, depression, and sleep disturbances. ${ }^{3}$

This difference between the noises supports the idea that the noise that was highlighted in the present study is smoother and causes a greater relaxation, since the high frequencies are not as evidenced as those of the white noise and the fact that among all noises, pink noise is the one that shows the greatest relation with the sounds of nature and can be used to generate sounds of rain, waterfall, wind, river and other natural sounds. ${ }^{39}$

Other variables may influence speech perception, regardless of the stimulus of the generator used, such as age, degree of hearing loss and previous experience that each individual brings in relation to this ability in a noisy environment.

The age should be considered since the aging process leads to several sensorial changes and one of the most frequent is hearing loss, which promotes changes from the ear anatomy ${ }^{40}$ to peripheral, central, and cognitive functions. ${ }^{41}$ From these changes, the elderly patient suffers as a consequence of altered speech perception, especially in the presence of noise since speech formers become more difficult to identify and separate from noise. ${ }^{42}$ In the present study, $71.4 \%$ of the participants were elderly, with age equability between the groups.

In addition, the study in question encompasses patients with sensorineural hearing loss in all groups, and researchers report that cochlear lesions tend to have a lowering of high frequencies ${ }^{43,44}$ and are responsible for much of the speech information. ${ }^{42}$ Therefore, the ability of speech perception in noise with lower thresholds at high frequencies could be more impaired compared with those with more preserved thresholds at these frequencies.

However, Killion ${ }^{45}$ reports that the difficulty of a patient to understand the speech in the noise cannot be foreseen only by the audiogram, that is, the arrangement of the thresholds that configure the loss does not measure the individual's ability to listen in competitive noisy environments.

Due to the wide variety of noise introduced in the HA market, the analysis of efficacy in the treatment of tinnitus and the influence of tinnitus on speech perception is essential for guiding professionals when adapting these sound generators.

According to the results obtained in the present study, we can suppose that there was no highlight to any specific stimulus regarding tinnitus annoyance. This occurred because all groups had similar responses in the evaluations

(-Tables $\mathbf{2}$ and $\mathbf{3}$ ).

Studies that investigate the efficacy of combined HAs do not usually pay attention to the acceptability of noise, although it is a very important factor for hearing comfort and to promote the effective use of HAs. ${ }^{14,46}$ Thus, it can be inferred that the professional during the programming process of the HA and more specifically the SG, at the moment of the noise selection, can choose the most comfortable for the patient, seeking the minimum of audibility that is able to promote relief of tinnitus.

However, the fact that pink noise stimulus has stood out in the evaluation of the perception of speech in the FN situation and, given the scarcity of studies in this area and the possible variables discussed, it is necessary to invest in future research on this subject.

\section{Conclusion}

The present study made it possible to conclude that the four noises were equally effective in relieving tinnitus, with no statistically significant differences between the analyzed groups.

Speech perception showed a statistically significant improvement in the speech situation in silence in all groups, regardless of the noise used.

In the noise situation, the pink noise stimulus was the only one that presented significant improvement.

Conflict of Interests

The authors declare that there is no conflict of interests.

\section{References}

1 Savage J, Waddell A. Tinnitus. BMJ Clin Evid 2014;2014:11

2 Shargorodsky J, Curhan GC, Farwell WR. Prevalence and characteristics of tinnitus among US adults. Am J Med 2010;123(08): 711-718

3 Kochkin S, Tyler RS, Born J. Marke Trak VIII: The prevalence of tinnitus in the United States and the Self-reported efficacy of various treatments. Hear Rev. 2011;18:10-27

4 Barros Suzuki FA, Suzuki FA, Yonamine FK, Onishi ET, Penido NO. Effectiveness of sound therapy in patients with tinnitus resistant to previous treatments: importance of adjustments. Rev Bras Otorrinolaringol (Engl Ed) 2016;82(03):297-303

5 Tunkel DE, Bauer CA, Sun GH, et al. Clinical practice guideline: tinnitus. Otolaryngol Head Neck Surg 2014;151(02):S1-S40

6 Searchfield GD. Sound therapy options. In: Tyler R. The Consumer Handbook on Tinnitus. Sedona, Ariz: Auricle Ink Publisher; 2008

7 Reavis KM, Rothholtz VS, Tang Q, Carroll JA, Djalilian H, Zeng FG. Temporary suppression of tinnitus by modulated sounds. J Assoc Res Otolaryngol 2012;13(04):561-571 
8 Tyler RS, Noble W, Coelho CB, Ji H. Tinnitus retraining therapy: mixing point and total masking are equally effective. Ear Hear 2012;33(05):588-594

9 Powers L, Munhóes SG. Acoustic therapy for the treatment of tinnitus: A primer. Hear Rev 2015;22(06):22

10 Amorim RMC, Almeida Kd. Estudo do benefício e da aclimatização em novos usuários de próteses auditivas. Pro Fono 2007;19(01): 39-48

11 Munro KJ, Lutman ME. The effect of speech presentation level on measurement of auditory acclimatization to amplified speech. J Acoust Soc Am 2003;114(01):484-495

12 Urnau D, Silva PAB, Seligman L. Influência do zumbido no índice percentual de reconhecimento de fala em pacientes normoouvintes. Int Arch Otorhinolaryngol 2010;14(04):450-455

13 Rocha AV, Mondelli MFCG. Aplicability of the real ear measurement for audiological intervention of tinnitus. Braz J Otothinolaryngol (Engl Ed) 2020;86(01):14-22

14 Tyler RS. Neurophysiological models, psychological models and treatments for tinnitus. In: Tyler RS. Tinnitus treatment: clinical protocols. New York: Thieme; 2006

15 Paula Erika Alves F, Cunha F, Onishi ET, Branco-Barreiro FCA, Ganança FF. Tinnitus handicap inventory: adaptação cultural para o Português Brasileiro. Pro Fono 2005;17(03):303-310

16 Flynn D, van Schaik P, van Wersch A. A comparison of multiitem likert and visual analogue scales for the assessment of transactionally defined coping. Eur J Psychol Assess 2004; 20:49-58

17 Santos GM. A influência do gerador de som associado à amplificação convencional para o controle do zumbido: ensaio clínico cego randomizado (tese). São Paulo: Faculdade de Medicina. 2012. Disponível em: http://www.teses.usp.br/teses/disponiveis/5/5143/tde-01112013-141148/pt-br.php

18 Rocha AV, Mondelli MFCG. Sound generator associated with the counseling in the treatment of tinnitus: evaluation of the effectiveness. Rev Bras Otorrinolaringol (Engl Ed) 2017;83(03):249-255

19 Bevilacqua MC, Banhara MR, Da Costa EA, Vignoly AB, Alvarenga KF. The Brazilian Portuguese hearing in noise test. Int J Audiol 2008;47(06):364-365

20 Carrabba L, Coad G, Constantini M, et al. Combination open ear instrument for tinnitus sound treatment. Proceedings of the $3^{\text {rd }}$. Tinnitus Research Initiative Meeting from Clinical Practice to Basic Neuroscience and Back. Stresa, Italy, 25; 2009

21 Burguetti FAR, Peloggia AG, Carvallo RMM. Limiares de audibilidade em altas frequências em indivíduos com queixa de zumbido. Int Arch Otorhinolaryngol 2004;8:4-6

22 Carvallo RMM, Koga M, Ishida I. Limiares de audibilidade para altas frequências em adultos sem queixa auditiva. Acta AWHO. 2002;21:2

23 Urnau D, Tochetto TM. Características do zumbido e da hiperacusia em indivíduos normo-ouvintes. Int Arch Otorhinolaryngol 2011;15:468-474

24 Menezes P, Santos Filha VAV. Acufenometria: o resgate de um instrumento de avaliação do zumbido e sua correlação com perdas auditivas sensoriais. Rev Fono Br. 2005;3:1-4

25 Pinto PCL, Sanchez TG, Tomita S. Avaliação da relação entre severidade do zumbido e perda auditiva, sexo e idade do paciente. Rev Bras Otorrinolaringol (Engl Ed) 2010;76:18-24

26 Sweetow RW, Sabes JH. Effects of acoustical stimuli delivered through hearing aids on tinnitus. J Am Acad Audiol 2010;21(07): 461-473
27 Parazzini M, Del Bo L, Jastreboff M, Tognola G, Ravazzani P. Open ear hearing aids in tinnitus therapy: An efficacy comparison with sound generators. Int J Audiol 2011;50(08):548-553

28 Oiticica J, Bittar RSM. Prevalência do zumbido na cidade de São Paulo. Rev Bras Otorrinolaringol (Engl Ed) 2015;81:167-176

29 Wazen JJ, Daugherty J, Pinsky K, et al. Evaluation of a customized acoustical stimulus system in the treatment of chronic tinnitus. Otol Neurotol 2011;32(04):710-716

30 Mondelli MFCG, Argentim JP, Rocha AV. Correlation between speech perception and tinnitus before and after the use of hearing aids. Audiol Commun Res 2016;21:e1649

31 Landgrebe M, Azevedo A, Baguley D, et al. Methodological aspects of clinical trials in tinnitus: a proposal for an international standard. J Psychosom Res 2012;73(02):112-121

32 Nascimento IDP. Relação entre o Tinnitus Handicap Invetory, acufenometria e avaliação visual analógica na avaliação do zumbido. Dissertação. Universidade Federal da Paraíba; 2015

33 Figueiredo RR, Azevedo AA, Oliveira PM. Análise da correlação entre a escala visual-análoga e o Tinnitus Handicap Inventory na avaliação de pacientes com zumbido. Rev Bras Otorrinolaringol (Engl Ed) 2009;75:76-79

34 Henning TR, Costa MJ, Urnau D, Becker KT, Schuster LC. Reconhecimento de fala de indivíduos normo-ouvintes com zumbido e hiperacusia. Int Arch Otorhinolaryngol 2011;15:21-28

35 Moon IJ, Won JH, Kang HW, Kim DH, An YH, Shim HJ. Influence of tinnitus on auditory spectral and temporal resolution and speech perception in tinnitus patients. J Neurosci 2015;35(42): 14260-14269

36 Gilles A, Schlee W, Rabau S, Wouters K, Fransen E, Van de Heyning P. Decreased speech-in-noise understanding in young adults with tinnitus. Front Neurosci 2016;10:288

37 Zhou J, Liu D, Li X, Ma J, Zhang J, Fang J. Pink noise: effect on complexity synchronization of brain activity and sleep consolidation. J Theor Biol 2012;306:68-72

38 Noreña AJ. An integrative model of tinnitus based on a central gain controlling neural sensitivity. Neurosci Biobehav Rev 2011;35 (05):1089-1109

39 Filho SN, Dalcastagnê AL. Geração de ruído rosa a partir do ruído branco. Seminário Brasileiro de Engenharia de Audio. UFMG. 2002

40 Chisolm TH, Willott JF, Lister JJ. The aging auditory system: anatomic and physiologic changes and implications for rehabilitation. Int J Audiol 2003;42(02, Suppl 2):S3-S10

41 Veras RP, Mattos LC. Audiologia do envelhecimento: revisão da literatura e perspectivas atuais. Rev Bras Otorrinolaringol (Engl Ed) $2007 ; 73: 128-134$

42 Edwards B. The distortion of auditory perception by sensioneural hearing impairment. AudiologyOnline. 2003 In: http://www. audiologyonline.com/articles_detail.asp?article_id=412

43 Araújo TdeM, lório MCM. Effect of sound amplification in speech perception in elderly with and without tinnitus. CoDAS 2015;27 (04):319-325

44 Kaya KH, Karaman Koç A, Sayın İ, et al. Etiological classification of presbycusis in Turkish population according to audiogram configuration. Kulak Burun Bogaz Ihtis Derg 2015;25(01):1-8

45 Killion MC. New thinking on hearing in noise: a generalized articulation index. Semin Hear 2002;23:57-75

46 Hoare DJ, Adjamian P, Sereda M, Hall DA. Recent technological advances in sound-based approaches to tinnitus treatment: a review of efficacy considered against putative physiological mechanisms. Noise Health 2013;15(63):107-116 